\title{
DIFERENÇA E INSUBORDINAÇÃO CRIATIVA: NEGOCIANDO SENTIDOS COM A AVALIAÇÃO ${ }^{1}$
}

\section{DIFFERENCE AND CREATIVE INSUBORDINATION: NEGOTIATING SENSES WITH ASSESSMENT}

\begin{abstract}
Maria Isabel Ramalho Ortigão
Professora da Faculdade de Educação da Universidade do Estado do Rio de Janeiro - UERJ e do Programa de Pós-graduação em Educação - ProPEd/UERJ. Rio de Janeiro, Brasil.

isabelortigao@terra.com.br

Renata Leite de Oliveira

Doutoranda em Educação (ProPEd/UERJ) e professora da rede municipal de Nova Iguaçu/RJ. renataoliveira ri@yahoo.com.br
\end{abstract}

\section{Resumo}

O presente texto tem por objetivo provocar uma reflexão sobre a temática da avaliação e diferença, negociando sentidos com as práticas de insubordinação criativa que emergem nos espaços escolares e ressignificam concepções educacionais, curriculares e avaliativas. Nossa perspectiva rompe com discursos normativos que buscam estabelecer critérios onde todos são avaliados da mesma maneira, desconsiderando as individualidades de cada sujeito. O processo avaliação-ensino-aprendizagem é desafiador e perpassa por concepções sobre educação, valores, políticas públicas e pelo próprio ato de avaliar. Uma concepção avaliativa que se baseia em um sujeito padrão, ou em um único perfil de aluno, exclui as diferenças e desconsidera a flexibilização curricular e avaliativa. Defendemos processos avaliativos com caráter mais formativo e processual, que amplie o olhar referente à aprendizagem, auxiliando o educador a traçar novas estratégias e práticas de acordo com cada contexto educacional. Acreditamos que por mais que existam tentativas de controle e de padronização tanto na avaliação e no currículo, como em relação a docentes e alunos, sempre haverá tentativas de escape da normatização. Desse modo enfatizamos o conceito de insubordinação criativa como estratégia e possibilidade de novas leituras educativas em prol das diferenças, que integram o ambiente escolar.

Palavras-chave: Avaliação da aprendizagem. Diferença. Insubordinação criativa.

1 Trabalho financiado pela Fundação de Apoio à Pesquisa do Estado do Rio de Janeiro - FAPERJ. 


\begin{abstract}
The present text aims at provoking a reflection on the theme of evaluation and difference, negotiating meanings with the practices of creative insubordination that emerge in the school spaces and re - signify educational, curricular and evaluative conceptions. Our perspective breaks with normative discourses that seek to establish criteria where all are evaluated in the same way, disregarding the individualities of each subject. The evaluation-teaching-learning process is challenging and permeates conceptions about education, values, public policies and by the very act of evaluating. An evaluative conception that is based on a standard subject, or on a single student profile, excludes differences and disregards curricular and evaluative flexibility. We defend evaluative processes with a more formative and procedural character, that broaden the look regarding learning, helping the educator to draw up new strategies and practices according to each educational context. We believe that even though there are attempts at control and standardization both in evaluation and in curriculum, as in relation to teachers and students, there will always be attempts to escape the normalization. In this way we emphasize the concept of creative insubordination as a strategy and possibility of new educational readings for the differences that integrate the school environment.
\end{abstract}

Key word: Learning assessment. Difference. Creative Insubordination

\title{
Introdução
}

A avaliação vem ganhando, nas últimas décadas, cada vez mais centralidade no campo educacional e tem nos colocado desafios em diferentes âmbitos - teóricos, metodológicos, práticos - em decorrência de mudanças nas sociedades. A redefinição de soberanias e a afirmação coletiva de identidades convivem em permanente tensão com projetos e percursos educacionais, muitas vezes em contextos - sociais, culturais, econômicos e políticos - instáveis.

O processo de redemocratização, instaurado a partir do fim do golpe militar no Brasil, acrescido pelo aumento da demanda social por educação, intensifica as tensões projetadas pelo confronto entre a promessa de universalização do direito à educação e a realização de processos excludentes nas escolas.

Nas últimas décadas, em especial, a partir de resultados de avaliações externas de estudantes (SAEB/Prova Brasil, PISA, ENEM, por exemplo), o debate sobre a permanência de desigualdades sociais na distribuição da educação brasileira permanece central e desafiador. Segundo Ortigão, Franco e Carvalho (2007), embora os indicadores educacionais evidenciem avanços na universalização da escola pública e, consequentemente, na democratização da composição social dos estudantes, os resultados dessas avaliações revelam a persistência de disparidades pronunciadas entre as condições das escolas frequentadas por alunos de diferentes origens sociais e étnicas, que estão relacionadas a desempenhos distintos e reforçam as diferenças sociais preexistentes. Revelam ainda que as escolas, mesmo as de uma mesma rede de ensino, 
são diferentes, não só pela diversidade de opções pedagógicas e gerenciais adotadas por cada uma ou pela variedade de práticas e estruturas internas - comprometimento dos docentes e ênfase dada aos processos de ensino e aprendizagem, por exemplo, mas, também, pela diversidade de estudantes que nelas estudam.

A partir dos diferenciados contextos educacionais torna-se necessário uma reflexão sociológica sobre a educação e, em especial, sobre a escola, em que se faz indispensável atender às origens sociais e culturais dos estudantes, compreendendo seus percursos individuais e coletivos como integrantes do processo de aprendizagem para todos, incluindo as diferenças que integram esses contextos. Assim, somos desafiados a reconstruir e a ressignificar nossas ideias, formulações e práticas para dar maior visibilidade e nitidez à face democrática da escola, às suas possibilidades emancipatórias, potencializando o diálogo entre os diferentes, com suas diferenças, reconhecendo as tensões, receios e contradições presentes no campo.

É nessa perspectiva que caminhamos neste texto. Aqui, nos desafiamos a refletir sobre a avaliação escolar, em matemática, em diálogo com a diferença e em articulação com as ideias de 'insubordinação criativa', propostas por D'Ambrósio e Lopes (2015). Para as autoras, tais ideias associam-se à noção de que "atrever-se a criar e ousar na ação docente decorre do desejo de promover uma aprendizagem na qual os estudantes atribuam significados ao conhecimento matemático" (Idem, p. 2).

Acreditamos no potencial da avaliação para promover aprendizagens e para melhorar o ensino e reconhecemos que mudanças são necessárias, na medida em que, segundo Fernandes (2009), a avaliação pode motivar ou desmotivar os estudantes, pode constituir importantes alavancas para superar obstáculos ou ser, ela mesma, mais um obstáculo para superar, pode ajudar os alunos a estudar e a compreender bem suas limitações e potencialidades ou, simplesmente, desinteressá-los.

Para que a avaliação não se torne mais um obstáculo no processo de aprendizagem é necessário romper com uma concepção avaliativa que somente julga e rotula, segregando os alunos que não seguem um padrão estabelecido. Precisamos avançar na direção de uma avaliação que oriente os alunos sobre suas capacidades, que os motive e provoque curiosidade em aprender, uma avaliação que não se preocupe somente com a nota enquanto resposta final do processo, mas que se preocupe com o processo de desenvolvimento de cada aluno, respeitando as singularidades de cada indivíduo.

A exigência de mudanças acerca da avaliação relaciona-se também ao desenvolvimento das teorias do currículo. Lopes e Macedo (2011) evidenciam o processo de construção e de significação que a ideia de currículo foi ganhando ao longo do tempo. Para as autoras, o desenvolvimento do campo foi repleto de lutas e embates políticos e ideológicos, tornando-se "uma luta política por sua própria significação, mas também pela significação do que vem a ser a sociedade, justiça social, emancipação, transformação social" (p. 253).

A avaliação, como parte integrante e constitutiva do currículo, é impregnada por essas lutas e embates, que produzem sentidos diferenciados e até conflitantes acerca da avaliação, suas metodologias e práticas avaliativas. 
Este texto está organizado em quatro seções, além desta introdução. $\mathrm{Na}$ continuidade, discutimos brevemente currículo e avaliação enfatizando um currículo para além de transmissão de conteúdos e de avaliações para além de meras mensurações; prosseguimos debatendo sobre avaliação e diferença em que questionamos uma avaliação na perspectiva da homogeneidade, mas sim, das diferenças reveladas no cotidiano das salas de aula. Na terceira seção, avaliação e insubordinação criativa, enfatizamos a necessidade de repensar a avaliação valorizando as diferenças e os processos de criatividade e insubordinação, rompendo com ideias tradicionais de que avaliar é determinar a "quantidade" de conhecimento dos estudantes em prol de uma construção coletiva de conhecimentos. Após estas seções, finalizamos a tessitura do texto com as considerações parciais, elaborando uma breve conclusão sobre avaliação, diferença e insubordinação criativa.

\section{Currículo e avaliação.}

A avaliação é apontada como peça central de reformas educacionais ocorridas em diversos países, em especial, a partir do final dos anos 1980. Brooke (2012, p. 325), ao realizar uma ampla revisão da literatura sobre as reformas educacionais ocorridas desde o final do século XX, afirma ser possível localizar estudos que evidenciam similaridades entre elas, "como se estivessem seguindo um receituário de políticas educacionais, algum tipo de orquestração ou, no mínimo, uma história de origens comuns" (BROOKE, 2012, p. 325).

De acordo com Afonso $(2007 ; 2009)$ é a partir dessa época que a avaliação ganha destaque como um dispositivo capaz de instituir mudanças no cenário social e educacional. Neste período, a avaliação em larga escala, as políticas de exames nacionais foram retomadas e ganharam cada vez mais visibilidade. Para o autor,

pelo menos nos países capitalistas ocidentais, as políticas de avaliação, de prestação de contas e de responsabilização (accountability) foram ganhando uma certa imunidade às concepções político-ideológicas dos governos, disseminando e homogeneizando muitos dos seus efeitos, como se essas mesmas políticas ganhassem o seu verdadeiro sentido situandose acima das realidades culturais, políticas, econômicas e educacionais nacionais. Esta tendência, entre outras consequências, tem aumentado a eficácia legitimadora destas políticas, tornando mais difícil desocultar os interesses, demandas e funções que lhe subjazem (AFONSO, 2009, p.17).

As avaliações e seus resultados, por um lado, tiveram o mérito de revelar os processos de desigualdades que permeiam os sistemas educativos, alertando a sociedade, de modo geral, acerca da distribuição desigual da educação (CARNOY et al, 2007; FRANCO et al, 2007; SCHEERENS, 2005, LEE e SMITH, 2002; ANYON, 1980). Por outro lado, têm surgido críticas bastante fortes às formas como as avaliações são conduzidas, às métricas utilizadas para monitorar o desempenho dos estudantes e para avaliar os sistemas educativos. Dentre tais críticas, destacam-se os estudos que evidenciam que as avaliações estão pautadas em uma lógica de mercado que justificam práticas meritocráticas, conduzem a uma compreensão estreita e reduzida do sentido de 
"qualidade", induzem a uma padronização da produção curricular, silenciando as diferenças e conduzindo a um processo de homogeneização nos sistemas educativos (ORTIGÃO e PEREIRA, 2016; TURA e PEREIRA, 2013; FREITAS, 2012; FERNANDES, 2009; RAVITCH, 2011; LUBIENSKI e LUBIENSKI, 2004, entre outros).

O convívio com diferentes políticas educacionais - curriculares, avaliativas, de formação de professores - proliferam sentidos que constituem o campo escolar, visando alcançar a qualidade educacional, garantindo a apropriação de diferentes conhecimentos e linguagens; reinventando a escola ao buscar formar cidadãos capazes de "sobreviver no mundo contemporâneo" (MOREIRA, 2013, p. 547).

Em tal convívio, conceitos e ideias, como qualidade e cidadania, articulam e negociam sentidos com (e entre) igualdade e diferença, influenciando o campo educacional com tentativas de padronizações das escolas e dos professores, dos currículos e das avaliações. São discursos que articulam sentidos de qualidade ${ }^{2}$ da educação associados a uma ideia de cidadania em que os conteúdos assumem uma dimensão instrumental.

Os processos e os resultados das avaliações possibilitam múltiplos discursos e leituras sobre questões que compõem o campo, tais como: currículo, formação de professores, defasagem idade-série, elaboração de políticas curriculares. A ampliação da avaliação a nível regional, nacional e/ou mundial, auxilia na perda da noção do contexto local e passa a ser enfatizada uma ideia de igualdade que negocia sentidos com a defesa de sistemas padronizados para que assim todos tenham os mesmos direitos, porém não há espaço para as diferenças e não se trabalha de maneira equitativa.

De acordo com Popkewitz (2013)

os mecanismos de mensuração dão magnitudes e correlações a abstrações específicas (ficções) que permeiam a conduta do mundo e têm o potencial de se materializar como aquilo que é aceito como real em educação" (p. 27).

Sem desconsiderar a sua importância, alertamos ser fundamental o questionamento desses processos avaliativos em que classificar e promover escalas de proficiência ou de notas se revela mais importante do que análises contextuais, que possibilitam ações coletivas e locais de construção e de produção curricular e de práticas avaliativas, desenvolvidas mediante processos de insubordinação criativa (D'AMBROSIO e LOPES, 2015).

Compreender a escola como um espaço político, composto pelas diferenças, auxilia na compreensão e construção de um currículo para além de transmissão de conteúdos, para avaliações além de meras mensurações e notas no boletim, e estimula que a criatividade surja no ambiente educacional. Essa percepção contribui para que a organização da escola e do currículo seja questionada, pois "toda universalidade pressuposta na ação educativa tem que ser desestabilizada com o questionamento do

\footnotetext{
${ }^{2}$ Qualidade é um conceito polissêmico, que invade o campo educacional, em especial, a partir do estabelecimento de sistemas avaliativos. Aqui usamos a ideia de qualidade associada à formação democrática, autônoma e crítica do sujeito.
} 
caráter monocultural da escola e das escolhas curriculares" (LOPES e MACEDO, 2011, p.193).

Em nossa perspectiva, compreendemos o currículo como uma prática cultural, na medida em que "funciona como um sistema de significações dentro do qual os sentidos são produzidos pelos sujeitos" (LOPES e MACEDO, 2011, p. 186). Por estas e outras razões, hoje, mais do que nunca, os sistemas educativos têm que alicerçar os seus currículos em princípios e orientações tais como os que nos são sugeridos por Shepard (2001):

- Todos os alunos podem aprender.

- Os conteúdos curriculares têm que ser suficientemente desafiadores para os alunos e estar orientados para o desenvolvimento de competências de resolução de problemas.

- A igualdade de oportunidades deve estar ao real alcance de todos os alunos, independentemente da sua diversidade.

- Todos os alunos são socializados nos discursos e nas práticas das disciplinas acadêmicas.

- Os alunos adotam hábitos de reflexão e atitudes favoráveis ao desenvolvimento das aprendizagens.

- Os alunos exercem práticas democráticas numa comunidade responsável e empenhada (p.1074).

É evidente que este tipo de princípios exige uma avaliação contextualizada, centrada nos processos e procedimentos, transparente e participativa por parte dos estudantes e de outros intervenientes. Não fará muito sentido insistir numa avaliação que se desenvolve pontualmente, defasada do processo de ensino e de aprendizagem, orientada para os produtos da aprendizagem e em que a participação dos sujeitos seja débil, ou mesmo, inexistente. Também não fará sentido uma avaliação que negue a diferença, que silencie o outro e sua singularidade, que não possibilite que o avaliado se expresse.

\section{Avaliação e diferença}

Pensar criticamente a avaliação educacional tem sido um enorme desafio. $\mathrm{Na}$ escola convivem velhos e novos problemas, velhas e novas soluções. Muitos estudos têm sido conduzidos com o intuito de compreender o cotidiano escolar e de se buscar alternativas às questões, que muitas vezes parecem insolúveis. Os resultados das avaliações externas, por exemplo, insistem em anunciar o baixo desempenho, especialmente, de escolas públicas. As altas taxas de reprovação e evasão são, segundo Esteban (2010, p. 46), questões que contribuem para 'naturalizar' o fracasso escolar. Um problema "significativo nas escolas que recebem crianças e jovens das classes populares" (Idem). Para a autora,

Nesse quadro, em que frequentemente se constata que a escola não é o que deveria ser, muitas perguntas retornam e encontram respostas que se repetem, mesmo quando são reconhecidamente insuficientes: padronizar os desempenhos validados, unificar os percursos de aprendizagem, uniformizar e intensificar o sistema de exames, classificar e reprovar (ESTEBAN, 2010, p. 47). 
Tentativas de responder aos problemas escolares tomam por base uma ideia de qualidade excludente. Algumas chegam a propor 'receitas' para serem copiadas e transplantadas. São propostas que normatizam os sujeitos, padronizam culturas, processos e práticas. Propostas essas que, segundo Esteban (2010, p. 48) impõe a "exclusão da diferença, a negação da alteridade e tenta ajustar o outro às identidades fixadas pelo modelo hegemônico e segregação daqueles que não se conformam às normas".

As padronizações das avaliações incorporam teses culturais sobre o que o sujeito é e o que ele deveria ser, e quem esse sujeito não é. Neste sentido, tentam criar ideias acerca do 'bom aluno', do 'bom professor', das 'boas práticas pedagógicas', da 'boa instituição escolar', fortalecendo binarismos e exclusões. Além disso, tentam naturalizar a ideia de que apenas poucos estudantes podem 'passar' ou ganhar boas notas nos cursos de matemática. Essa lógica, segundo Popkewitz (2013, p. 41), impulsiona "a produção de tipos humanos nas escolas e acarreta um processo concomitante de exclusão e abjeção representado pelo impulso da inclusão".

Nessa mesma perspectiva analítica, Valero (2016) afirma que a constituição histórica das matemáticas sempre foi um domínio masculino, produzido em sua grande maioria por homens em uma configuração de sociedades patriarcais onde o 'outro' (feminino) fica posicionado como inferior em força, corpo e intelecto. Segundo a autora, essas ideias terminam por naturalizar os baixos desempenhos em matemática das mulheres em provas de larga escala. Para ela,

Como parte dos processos históricos de governança e gestão da população, as diferenciações foram criadas em termos de habilidade, gênero, raça, linguagem, classe social, status socioeconômico, etnia, religião, orientação sexual, etc. Essas diferenças não são geradas exclusivamente na escola, mas estas, além de reproduzi-las, as reforça. Além disso, as pedagogias e os processos educacionais que fazem parte do currículo de matemática muitas vezes tendem a contribuir para essa reprodução e exacerbam as desigualdades entre estudantes e suas possibilidades, tendo em vista o valor social atribuído ao bom desempenho em matemática (VALERO, 2017, p. 113. Tradução nossa.).

Tal lógica se mantém ativa por intermédio de processos ativos de exclusão baseados em construções estereotípicas de gênero, raça, classe, habilidade e várias outras configurações de posição de sujeito.

Essas perspectivas auxiliam a pensar em processos de subjetivação e em processos de identificações provisórias, rompendo com concepções essencialistas de identidade. Um processo em que nos tornamos sujeitos quando somos convocados a tomar uma decisão. Um processo de diferimento, de marcação simbólica que define quem está incluído ou excluído das práticas e das relações sociais. Desta forma, o espaço escolar está inserido em incessantes processos de construção de identificações e de significações por intermédio da linguagem.

A noção de diferença cultural, discutida por Bhabha (1998, p. 63), como processo de significação pelo qual "afirmações da cultura ou sobre a cultura diferenciam, discriminam e autorizam a produção de campos de força, referência, aplicabilidade e 
capacidade é significativo para pensar os processos escolares de produção e de conformação à desigualdade. Para o autor,

A diferença cultural cria a instabilidade e adquire novos matizes por ser aprendida como resultado de práticas discriminatórias e produzidas como signo de autoridade. (BHABHA, 1998, p. 166).

Essa ideia coloca em suspeição a cultura como elemento de unificação e produção de homogeneidade e faz emergir a compreensão da cultura como produção no espaço contraditório e ambivalente da enunciação, tecido híbrido, como significados e símbolos fluidos.

Emana dessas noções a convicção de que distintos saberes e modos de vida, ou seus fragmentos, ocupam os espaços escolares e se mantém em interação com a produção hegemônica, criando novas significações, relações e contextos que não podem ser demarcados por antagonismos, nem eliminados pelo compromisso da homogeneidade. A esses 'espaços', Bhabha (1998) denomina de entre-lugar, um espaçotempo intersticial de produção de novas significações, em que a relação entre os opostos produz novas possibilidades de articulações do discurso e da ação. Para o autor, neles, dialogam permanência e ausência, o que é aceito e o que é negado, o dito e o silenciado, a contradição, a diferença e a pluralidade. Diálogos marcados pela tensão, pelo desconforto, pela instabilidade, pela fluidez das fronteiras.

A avaliação é uma das práticas escolares em que permanência e mudança convivem, em constante disputa de sentidos e em negociação. Segundo Esteban (2010, p. 66),

\begin{abstract}
A avaliação classificatória só pode se realizar tendo como referência um único padrão de conhecimento e de percurso de aprendizagem válido, constituído a partir do que é definido como cultura legítima. Porém, ao lidar com a diferença, necessariamente presente no cotidiano escolar, a avaliação emerge como discurso ambivalente que atua no sentido da normatização proposta pelo projeto escolar e como um dispositivo que pode expressar a diferença cultural.
\end{abstract}

A avaliação, quando constituída na perspectiva da homogeneidade, ignora as diferenças reveladas no cotidiano das salas de aula, em que as respostas 'certas' são consideradas as 'aprendizagens' dos estudantes e, por sua vez, as respostas 'erradas' representam o 'não saber'.

Um exemplo dessa perspectiva avaliativa pode ser identificado na seguinte cena, adaptada de Sztajn e Ortigão (2008, p. 69).

A professora entra em sala e seus alunos já estão arrumados, em fila, um atrás do outro. É dia de prova e não é permitido fazer perguntas, nem olhar para o que o seu colega está fazendo. Em dia de prova é cada um por si! Ao término do tempo estabelecido, a professora pede que os estudantes entreguem a prova. Em casa, ela corrige o que os estudantes acertaram e dá uma nota. Ela fica surpresa com o resultado de alguns alunos, pois ela imaginava que estes estavam entendendo... Mas, prova é prova e não se pode discutir com as respostas que cada aluno deu. 
A cena, comum em muitas salas de aula, revela que, para essa professora, a avaliação é formal, individual e silenciosa. O foco está nos acertos (e na nota) e são eles que irão informar se os alunos aprenderam. Os erros e os processos individuais são ignorados e negligenciados.

Romper com essa perspectiva é um desafio àqueles e àquelas que desejam construir uma escola inclusiva, participativa e democrática. Uma escola em que a avaliação não seja sinônimo de prova e que a aprendizagem não seja expressa pelos acertos e pela nota. Pensar nesses desafios remete-nos a praticar uma outra avaliação, mais formativa, inclusiva e emancipatória e que reconheça o outro como legítimo. Remete-nos praticar uma insubordinação criativa.

\section{Avaliação e insubordinação criativa}

Nos campos da Educação e da Educação Matemática, as últimas três décadas foram significativas em relação ao desenvolvimento de teorias e/ou concepções renovadas de currículo, das aprendizagens e da avaliação. Especificamente em relação à avaliação, hoje sabemos que os estudantes constroem conhecimento criando suas próprias interpretações, seus modos de organizar a informação e suas abordagens para resolver problemas.

É nesse sentido que tem se afirmado a necessidade de se repensar a avaliação em direção a ações que valorizem os saberes das crianças e dos jovens e seus modos próprios de pensar e construir conhecimento, que não são homogêneos. $E$ mais, que recorram a tarefas mais abertas e variadas, diversifiquem as estratégias e os instrumentos avaliativos, analisem de forma sistemática a produção dos estudantes e seu processo de desenvolvimento, contribuam para motivar os estudantes e valorizem os processos de comunicação para que eles explicitem os procedimentos usados. Uma avaliação baseada em valores éticos e de justiça social, que respeite as diferenças, que promova a reflexão e a autonomia dos educandos.

Defendemos que nossos esforços precisam direcionar as práticas avaliativas nas escolas e nas salas de aula no sentido dessa necessária, desejável e imprescindível concretização de outras práticas de ensino e de avaliação que tornem as salas de aula e, consequentemente, os sistemas educativos mais democráticos, mais inclusivos e mais adequados às exigências das sociedades atuais e às legítimas aspirações, necessidades e direitos das crianças e dos jovens. É nesta direção que Domingos Fernandes (2009), afirma a necessidade de se repensar a avaliação de modo a se considerar que

(a) as tarefas sejam suficientemente desafiadoras para os estudantes, (b) haja uma clara preocupação com os processos de aprendizagem e também, naturalmente, com os produtos, (c) a avaliação seja contínua e integrada no processo de ensino e aprendizagem e os alunos participem ativamente no processo de avaliação. (FERNANDES, 2009, p. 39).

Ao repensar o processo avaliativo nessa perspectiva nos aproximamos das ideias de 'insubordinação criativa', que, segundo D'Ambrósio e Lopes (2015) "é legitimada por centrarem-se em práticas profissionais alicerçadas em bases éticas, morais e de justiça 
social" (p.3). Para as autoras, "atrever-se a criar e ousar na ação docente decorre do desejo de promover uma aprendizagem na qual os estudantes atribuam significados ao conhecimento matemático" (D’AMBRÓSIO e LOPES, 2015, p. 2), o que exige, por parte dos professores uma construção coletiva, responsável e situada nos contextos educativos locais.

As tensões geradas na reflexão entre políticas públicas e a análise do contexto educacional local, o comprometimento com a aprendizagem dos educandos com base no respeito e consideração dos contextos locais negociam sentidos com ações subversivas, criativas e responsáveis.

Assim, outro olhar para a avaliação e para os processos de ensino-aprendizagem parte de um exercício da autonomia que se traduz na necessidade de

envolver-se em um processo contínuo de descobertas e transformações das diferenças entre a prática cotidiana e as aspirações sociais de igualdade, justiça e democracia; de compreensão dos fatores que dificultam não apenas as alterações de condições sociais e institucionais do ensino, como também nossa própria consciência (D’AMBRÓSIO e LOPES, 2015, p.9).

Essa visão sobre o ensino e a aprendizagem da matemática e consequentemente sobre a avaliação conduz à procura de alternativas que rompam com ideias tradicionais de que avaliar é determinar a "quantidade" de conhecimento dos estudantes, uma perspectiva inadequada uma vez que hoje se reconhece que "a aprendizagem não é uma questão de acumulação de conhecimentos, mas, sim, de construção" (SZTAJN e ORTIGÃO, 2008, p. 69). Por isso, a avaliação em matemática não pode reduzir-se a medir quanta informação os estudantes possuem, devendo, isto sim, preocupar-se em determinar, para cada um, até que ponto vai sua capacidade e disposição para usar e comunicar essa informação (ABRANTES, s/d; BURIASCO, 2004; VIOLA DOS SANTOS, 2015).

No cotidiano da escola, os diferentes modos de aprender, de compreender o ensinado e o discutido com os estudantes evidenciam trajetórias variadas e singulares vivenciadas pelas crianças e jovens. Segundo Sampaio (2010), é preciso valorizar a diferença, não a igualdade.

Diferença. Sempre diferença, e não igualdade de caminhos, aprendizados, conhecimentos, desconhecimentos, conforme aprendemos. O processo de aprendizagem/ensino é constituído pela diferença, pela responsabilidade frente à singularidade e alteridade do outro (SAMPAIO, 2010, p. 73).

A avaliação classificatória, apesar de polêmica, é ainda hegemônica nas ações avaliativas nas salas de aula de matemática. Tais avaliações pouco ou nada contribuem para o ensino/aprendizagem, em especial, por desconsiderar os percursos, ritmos, lógicas, resultados diferentes dos esperados pela 'norma'. Essas avaliações centram-se no produto, nos resultados dos estudantes, ignorando o processo.

Romper com essa perspectiva 'tradicional', insubordinar-se ao 'estabelecido', criar outro processo avaliativo que inclua a todos, respeitando suas diferenças e particularidades é um desafio que está posto. Como valorizar os conhecimentos ainda 
frágeis, mas potencialmente importantes do ponto de vista social, cultural, mas também da própria matemática? Que estratégias avaliativas usar de modo a ampliar os conhecimentos dos estudantes? Como avaliar os estudantes sem desqualificar seus modos próprios, individuais (e legítimos) de pensar e se comunicar? São questões, que nós, professores e professoras, precisamos, cotidianamente, buscar responder, tendo como referência uma escola inclusiva, democrática e solidária.

Á título de ilustração e problematização, trazemos a cena a seguir que ilustra a prática avaliativa de uma professora.

Quando Priscila entra em sala seus alunos já estão sentados em dupla para a aula de matemática. Eles aguardam o problema-desafio que a professora sempre propõe. Animados eles conversam sobre o problema enquanto Priscila circula pela sala, para em cada dupla para ouvir o que eles estão fazendo e como estão pensando. Ela faz perguntas que Ihes permitem saber que caminhos estão seguindo. Quando todos terminam, ela pede aos alunos que exponham suas ideias sobre como resolveram o problema e qual a resposta encontrada. A turma discute as diferentes soluções e resultados para chegar a uma conclusão sobre qual está correto, ou mesmo se é possível aceitar mais de um. Em casa, ela relembra o que aconteceu e como seus alunos resolveram. Ela toma nota sobre as dificuldades que cada um teve e os pontos onde foi fácil resolver as perguntas que apareceram. Com isso, ela busca saber o que cada aluno aprendeu, o quanto ele caminhou, e o que é preciso fazer para ele avançar ainda mais. (Adaptado de SZTAJN e ORTIGAO, 2008, p. 69)

Para Priscila o momento de avaliação não se diferencia de uma aula, mas dela é parte integrante. Mesmo estando em duplas ela avalia cada um de seus alunos. Ela os escuta e estimula que eles falem o que pensam e como pensam. Ela os faz escutar seus colegas e os conduz a refletir sobre os procedimentos, soluções e respostas aos problemas, os acertos e os equívocos e as soluções possíveis aos problemas.

Como tarefa complementar, ela sugere que os alunos, individualmente, elaborem relatórios sobre a aula. Eles devem relatar como sua dupla resolveu o problema-desafio, que dificuldades sentiram e como chegaram à resposta. Também precisam relatar a discussão ocorrida com todos os alunos e em que medida eles concordam ou discordam das soluções e respostas encontradas por seus colegas. Para Priscila, ao propor tal tarefa, ela atende a uma exigência da escola em relação à avaliação individual (ORTIGÃO, 2016).

Tal concepção avaliativa rompe com uma avaliação tradicional e normativa e tenta compreender os diferentes caminhos trilhados pelos alunos até o conhecimento e/ou a elaboração do conhecimento proposto a partir de uma questão. Este processo avaliativo ultrapassa a mera quantificação, ele incentiva e explora a criatividade, contribuindo para que os alunos desenvolvam o máximo possível suas competências.

\section{Considerações}

O sistema educacional está inserido em um campo de (re)significações e de constantes negociações que se processam cotidianamente. A escola é o local onde as 
diferenças proliferam e se entrecruzam, um espaço de disputa e de (re)significações de sentidos. Compreender a escola como espaço-tempo de produção curricular perpassado por diferentes sentidos culturais (como avaliação e diferença) em permanente negociação/tradução é uma alternativa interessante para desconstruir práticas naturalizadas que sustentam processos de discriminação e exclusão.

Conforme salientado por D’Ambrósio e Lopes (2015)

cabe analisar nossas ações profissionais e avaliar se não temos privilegiado responder positivamente às políticas públicas e institucionais, sem perceber que podemos, colaborativamente, superar a crença nessa formação que prioriza o domínio do conteúdo matemático, em detrimento de uma formação mais global e plena, que possibilite a constituição de uma identidade profissional pautada em princípios éticos e solidários ( $p$. 14).

Pensar no processo educacional também é ressignificar o que compreendemos por currículo, avaliação e diferença. Se seguirmos "moldes" avaliativos onde a prova é o mais importante e a nota é o espelho da aprendizagem do aluno, ainda estaremos vinculados a uma perspectiva homogeneizante e excludente de escola e de educação. Mas, se compreendermos o currículo para além de um conjunto de disciplinas, um espaço de construção coletiva de conhecimentos, onde a avaliação auxilia docentes e estudantes a entenderem os processos de construção de aprendizagens, um outro olhar se desenha. Nele, currículo e avaliação são entendidos como construção coletiva e inacabada e valorizam-se as diferenças que nos constituem enquanto sujeitos sociais.

É importante lembrar que nenhum sistema educacional está isolado de um contexto social, econômico e cultural a que ele atende, desta maneira enfatizamos a urgência em romper com tentativas que buscam regular e enquadrar a diferença a um padrão dominante, excluindo quem foge à regra estabelecida. As instituições de ensino possuem um relevante papel no processo de incorporação das diferenças, o de desconstruir hegemonias e problematizar as pretensões de universalidade contribuindo para a desestabilização do status quo, rompendo com padrões pré-estabelecidos e com as tentativas de impedir que as diferenças possam emergir.

Portanto, consideramos o currículo como um híbrido de constante negociação e enunciação, onde as diferenças podem encontrar um espaço para produzirem sentidos, dialogarem e negociarem, sempre dentro de um processo articulatório no qual a criatividade adquire espaço e a avaliação rompe com processos de hierarquização de conhecimentos e de somatório de notas apoderando-se de um viés de responsabilidade e criatividade nos processos educativos.

\section{Referências}

ABRANTES, P. Avaliação e educação matemática. Rio de Janeiro: Universidade Santa Ursula/GEPEM, p. 16, sem data.

AFONSO, A. J. Estado, políticas educacionais e obsessão avaliativa. Revista Contrapontos, Itajaí, v. 7, n. 1, p. 11-22, 2007. 
AFONSO, A. J. Nem tudo o que conta é mensurável ou comparável. Crítica à accountability baseada em testes estandardizados e rankings escolares. Revista Lusófona de Educação, Lisboa, v. 13, n.1, p. 13-29, 2009.

ANYON, J. Social class and the hidden curriculum at work. Journal of Education, Boston, 162(1), 67-92, 1980.

BHABHA, H. O local da cultura. Belo Horizonte: UFMG, 1998.

BROOKE, N. (Org.) Marcos Históricos na Reforma da Educação. Belo Horizonte: Fino Traço, 2012.

BURIASCO, R. L. C. de. Análise da produção escrita: a busca do conhecimento escondido. In: ROMANOWSKI, J. P.; MARTINS, P. L. O.; JUNQUEIRA, S. A. (Org). Conhecimento local e conhecimento universal: a aula e os campos do conhecimento. Curitiba: Champagnat, p.243-251, 2004.

CARNOY, M., GOVE, A. K. \& MARSHALL, J. H. Cuba's Academic Advantage. Why students in Cuba do better in school. Board of Trustees of the Leland Stanford Junior University. California: Stanford University Press, 2007.

D'AMBROSIO B. S.; LOPES C. E. Insubordinação Criativa: um convite à reinvenção do educador matemático. Bolema. Rio Claro (SP), v. 29, n. 51, p. 1-17, abr. 2015. (DOI: http://dx.doi.org/10.1590/1980-4415v29n51a01). Disponível em: http://www.scielo.br/pdf/bolema/v29n51/1980-4415-bolema-29-51-0001.pdf. Acesso em: $15 / 07 / 2017$.

ESTEBAN, M.T. Diferença, aprendizagens e avaliação: perspectiva pós-colonial. In: ESTEBAN e AFONSO (Orgs.). Olhares e Interfaces. Reflexões críticas sobre a avaliação. São Paulo: Ed. Cortês, pp. 45-70, 2010.

FERNANDES, D. Articulação da aprendizagem, da avaliação e do ensino: questões teóricas, práticas e metodológicas. In: ALVES, M. P.; DE KKETELE, JM. (Orgs.). Do currículo à avaliação, da avaliação ao currículo. (Coleção Educação e Formação). Porto/Portugal: Porto Editora, pp. 131-142, 2011.

FERNANDES, D. Avaliar para Aprender. Fundamentos, práticas e políticas. São Paulo: Editora UNESP, 2009.

FERNANDES, D. Para uma teoria da avaliação no domínio das aprendizagens. Estudos em Avaliação Educacional. v. 19, n. 41, set./dez. 2008.

FRANCO, C., SZTAJN, P. e ORTIGÃO, M I R. Mathematics teachers, reform and equity: results from the Brazilian national assessment. Journal for Research in Mathematics Education, Reston, 38 (4), 393-419, 2007.

FREITAS, L. C. Os reformadores empresariais da educação: da desmoralização do magistério à destruição do sistema público de educação. Educação \& Sociedade, 119, 379-404, 2012. Retirado de http://www.scielo.br/pdf/es/v33n119/a04v33n119.pdf.

LEE, V. \& SMITH, J. B. Tamanho da Escola: qual é o mais efetivo e para quem? Estudos em Avaliação Educacional, São Paulo, 25, 77-121, 2002. Retirado de http://publicacoes.fcc.org.br/ojs/index.php/eae/article/view/2192. 
LOPES, A. C. e MACEDO, E. Teorias de Currículo. São Paulo: Cortez, 2011.

LUBIENSKI, C., \& LUBIENSKI, S. The public school advantage: why public scholls outperform private schools. Chicago: The University of Chicago Press, 2004.

MOREIRA, A. F. B. Currículo e gestão: propondo uma parceria. Ensaio, 21 (80), p. 547562, 2013.

ORTIGÃO, M. I. R. Práticas avaliativas em matemática na escola básica. In: XII Colóquio sobre Questões Curriculares, VIII Colóquio Luso-Braslieiro, 2016, Recife: ANPAE, 2016. v. 1. p. 880-889.

ORTIGÃO, M. I. R. e PEREIRA T. V. Homogeneização curricular e o sistema de avaliação nacional brasileiro: o caso do estado do Rio de Janeiro. Educação Sociedade \& Cultura. (Edição especial: Avaliação das escolas: políticas, perspectivas e práticas), 2016. Disponível em: http://www.fpce.up.pt/ciie/sites/default/files/ESC47Maria.pdf. Acesso em 10/09/2016.

ORTIGÃO, M. I. R., FRANCO, C., F. e CARVALHO, J. B. P. A distribuição social do currículo de matemática: quem tem acesso a tratamento da informação? Educação Matemática Pesquisa, São Paulo, 9(2), 249 - 273, 2007. Disponível em: http://revistas.pucsp.br/index.php/emp/article/viewFile/904/597. Acesso em: 10/08/2017.

POPKEWITZ, T. Números em grades de inteligibilidade dando sentido à verdade educacional. In: TURA, M. L.; G, M. M. (orgs.) Currículo, políticas e ação docente. Rio de Janeiro, EdUERJ, 2013.

RAVITCH, D. Vida e morte do grande sistema escolar americano: Como os testes padronizados e o modelo de mercado ameaçam a educação. Porto Alegre: Sulina, 2011.

SAMPAIO, C. S. Relações de aprendizagem (e ensino) na escola de Ensino Fundamental: (in)temporalidades da participação na avaliação pedagógica. In: ESTEBAN, M. T. e AFONSO, A. J. (Orgs.). Olhares e Interfaces - Reflexõs críticas sobre a avaliação. São Paulo: Cortez, pp. 71-95, 2010.

SCHEERENS, J. Review and meta-analyses of school and teaching effectiveness. Book Report. Department of Educational Organization and Management University of Twente. The Netherlands, 2005.2 Retirado de https://www.utwente.nl/bms/omd/Medewerkers/artikelen/scheerens/rev-metaanalysis2007.PDF

SHEPARD, L. The role classroom assessment in teaching and learning. In: RICHARDSON, V. Handbook of research on teaching. American Education Resarch Associatin. New York: Macmillan, 2001

SZTAJN, P.; ORTIGÃO, M. I. R. Noções logico-matemáticas: perspectivas da avaliação diagnóstica. Secretaria Municipal de Educação do Rio de Janeiro: Revista Convívio, pp. 67-77, Setembro/2008.

TURA, M. L. R. \& PEREIRA, T.P. Políticas curriculares, sistemas de avaliação e conhecimentos escolares. In: Maria de Lourdes R. Tura, \& Maria Malta A. Garcia (Org.). Currículo, políticas e ação docente, pp. 111-125, 2013. Rio de Janeiro: EdUERJ. 
VALERO, P. El deseo de acceso y equidade em la educación matemática. Revista Colombiana de Educación, N. 73, pp. 99-128, 2017. Disponível em: http://revistas.pedagogica.edu.co/index.php/RCE/issue/view/500/showToc. Acesso em: 15/08/2017.

VIOLA DOS SANTOS, J. R. Discussões de professores de matemática a respeito da avaliação em um grupo de trabalho. Trabalho apresentado no VI SIPEM. Pirenópolis, 2015.

Disponível em:

http://www.sbembrasil.org.br/visipem/anais/story_content/external_files/DISCUSS\%C3\%9 5ES\%20DE\%20PROFESSORES\%20DE\%20MATEM\%C3\%81TICA\%20A\%20RESPEITO \%20DA\%20AVALIA\%C3\%87\%C3\%830\%20EM\%20UM\%20GRUPO\%20DE\%20TRABAL HO.pdf. Acesso em: 20/06/2016.

Submissão: 15/08/2017

Aceite: 10/11/2017 